\title{
Multicultural coping experiences of parents following perinatal loss: A meta-ethnographic synthesis
}

\author{
Sara Fernández-Basanta MSc, BSN, Carmen Coronado PhD, BPharm, María-Jesús \\ Movilla-Fernández PhD, MSc, BSN
}

Research group GRINCAR, Department of Health Sciences, Faculty of Nursing and Podiatry, University of A Coruña, Ferrol, Spain

\begin{abstract}
Aims. To synthesize research findings regarding the coping experiences of parents following perinatal loss. Design. Noblit and Hare's interpretive meta-ethnography was followed.

Data Sources. A comprehensive systematic search of the published literature (2013-2018) was undertaken in five databases, complemented by supplementary searches.

Review Methods. Fourteen studies met the research objective and inclusion criteria.

Results. Five themes describe the coping strategies used by parents who experience perinatal loss. The themes were synthesized into the metaphor Staying afloat in the storm.

Conclusion. Parents use coping strategies to manage perinatal loss and the use of these strategies is conditioned by cultural, social, and individual factors. This study has implications for evidence-based practice by showing care needs and the importance of implementing emotional and patient-centred care interventions.

Impact. This meta-ethnography highlights the care needs of parents following perinatal loss, facilitating understanding of coping experiences. Increased knowledge about these experiences may contribute to the development and implementation of nursing and midwifery interventions that include emotional and patient-centred care.
\end{abstract}

\section{Keywords}

Coping, grief, literature review, meta-ethnography, midwives, nurses, perinatal death, qualitative research, systematic review 


\section{INTRODUCTION}

Parental bereavement is the experience of parents that begins following perinatal loss. The World Health Organization (2006) reports that the perinatal period ranges from 22 weeks of gestation to one week of independent life. However, this period is often extended in practice and in the literature (Fenstermacher \& Hupcey, 2013; López García de Madinabeitia, 2011). In this meta-ethnography, perinatal loss is referred to as the loss of a foetus or baby due to a miscarriage, termination of pregnancy due to foetal anomalies (TFA), stillbirth, or neonatal death.

The available research recognizes the special features of perinatal bereavement, as it entails multiple losses for parents (Dallay, 2013). Despite the trauma of perinatal loss, individuals can still develop a healthy connection with the deceased child and it may even be a transformative grief experience if they receive comprehensive support from healthcare providers (HCPs), especially nursing staff (Cacciatore, 2010).

\subsection{Background}

Perinatal loss causes a set of painful emotional reactions to which grieving parents must respond. Shortterm reactions include shock, anger, emptiness, helplessness, and loneliness; long-term reactions may include depression, anxiety, and post-traumatic stress disorder (PTSD) (Flenady et al., 2014; Koopmans, Wilson, Cacciatore, \& Flenady, 2013). Some of these emotions are exacerbated in subsequent pregnancies following the loss (Côté-Arsenault \& Marshall, 2000). Parents use coping strategies to reduce, manage, and live with the natural physical, mental, and emotional symptoms of grief (Puigarnau, 2008).

Perinatal mortality has been reduced by scientific advances and improved healthcare quality for pregnant women and new-borns (Dallay, 2013; Koopmans et al., 2013). Nevertheless, between 20\%-30\% of pregnancies end in miscarriage worldwide (Meaney, Corcoran, Spillane, \& O'Donoghue, 2017). Furthermore, the rate of foetal death was $18.4 \%$ of all births, representing 2.6 million foetal deaths worldwide in 2015 (Lawn et al., 2016). However, the literature establishes the possibility that these statistics are underestimated due to the under-registration of deaths. The social undervaluation of these losses and the lack of support given to parents could explain this under-registration (Flenady et al., 2014; Frøen et al., 2011).

Despite the significant psychological impact on parents and the prevalence of these losses, HCPs find the care of bereaved parents stressful and challenging and feel unprepared to support these parents (MartinezSerrano, Palmar-Santos, Solis-Munoz, Alvarez-Plaza, \& Pedraz-Marcos, 2018). Instead, HCPs tend to address clinical care, while emotional care is often disregarded (Ellis et al., 2016; Lee, 2012). They receive little or no training in providing care in the context of these losses, making it difficult for HCPs to address the emotional sphere (Nuzum, Meaney, \& O'Donoghue, 2014). What is clear from the available literature is that the provision of care to these families is crucial to prevent negative short- and long-term outcomes and that HCPs need training to manage the attention given to these parents. This is especially the case for nurses and midwives, who are the reference professionals for parents in pregnancy loss care (Ellis et al., 2016; Gold, 2007; Martinez-Serrano et al., 2018).

Cochrane Collaboration published a systematic review about support for parents and their families following perinatal death (Koopmans et al., 2013). Due to the high loss-to-follow-up rate, the three identified trials could not be analysed. As a result, the authors of the review recommended that other designs should be used to inform practice (Ellis et al., 2016; Koopmans et al., 2013). No previous publications have systematically analysed the available evidence on the coping experiences of both women and men following perinatal loss. This qualitative review provides a rich account of these coping experiences and a more in-depth understanding of this complex phenomenon. The findings of this metaethnography provide a basis of evidence for nursing and midwifery clinical practice. 


\section{THE REVIEW}

\subsection{Aims}

This qualitative review aims to synthesize the available body of qualitative work regarding how parents cope with perinatal loss.

\subsection{Design}

We conducted a systematic review of qualitative studies using meta-ethnography to synthesize the studies with an inductive and interpretive analysis (Noblit \& Hare, 1988). The review has been written in accordance with the eMERGe reporting guidance (France et al., 2019). The research question used to guide the search strategy was as follows: How do parents cope with perinatal loss?

\subsection{Search methods}

A comprehensive systematic search strategy was undertaken in the PubMed, Scopus, CINAHL, PsychINFO, and Web of Science databases in July 2018. This search was complemented with supplementary searches involving reference checking and searching for cited articles.

Search terms were developed from the research question using the SPIDER tool (File S1) (Cooke, Smith, \& Booth, 2012). Medical Subject Headings, CINAHL descriptors and free terms were used as search terms. The Boolean operator "AND" was used to relate the search queries in SPIDER (terms in different columns). Truncations were employed to ensure a broad search. The limits selected in the databases were publication date (between 2013-2018) and language (English, Portuguese, and Spanish). We decided to set the start of the time range after the publication of the Cochrane systematic review (Koopmans et al., 2013).

Papers were included if they were original qualitative articles or mixed articles from which the qualitative results could be extracted published between 2013 and July 2018. They were focused on the experience of parents following perinatal loss. Inclusion was restricted to studies whose sample comprised mothers, fathers or parents and whose type of loss was miscarriage, TFA, foetal death, or neonatal loss. Grey literature, discussion or review papers and papers not in English, Portuguese, or Spanish were excluded.

\subsection{Search outcomes}

Database searches yielded 1,029 records and supplementary searches provided one additional record. The selection process of the articles began with the elimination of 281 duplicate articles. The titles and abstracts of the retrieved papers $(\mathrm{N}=749)$ were assessed against the inclusion and exclusion criteria. The full articles selected from the title and abstract screening $(\mathrm{N}=86)$ were examined in relation to the inclusion and exclusion criteria. At this stage, 72 papers were excluded for not being relevant to the phenomenon of interest or because of the sample, methodology, type of loss, type of paper or language. In both stages, the entire selection process was carried out individually by each author and in team sessions, the authors reached consensus. The final sample was 14 articles (Figure 1). 


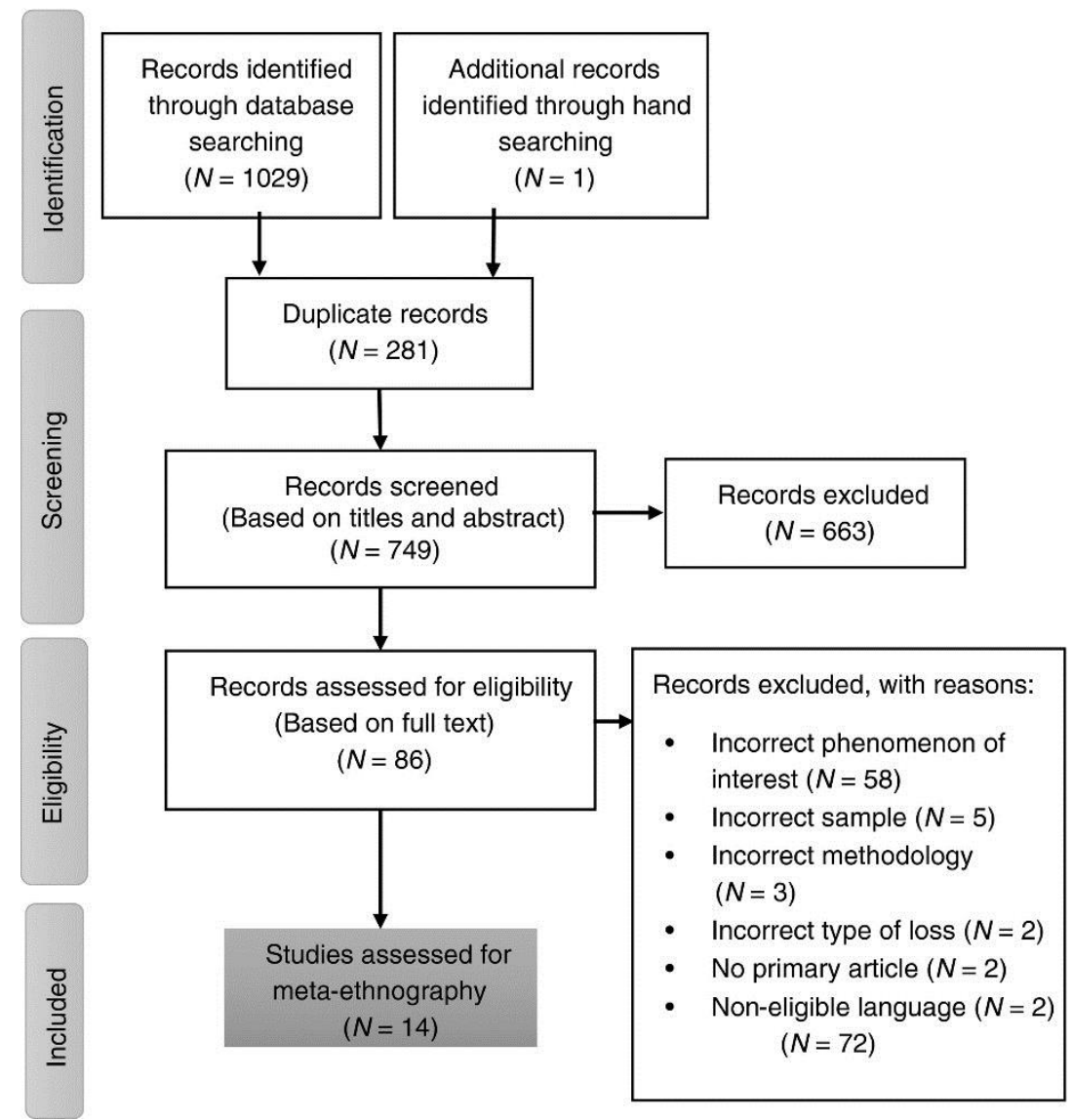

Figure 1. PRISMA flowchart

\subsection{Quality appraisal}

Each primary study was appraised using the Joanna Briggs Institute Qualitative Assessment and Review Instrument (QARI) (Joanna Briggs Institute, 2017) for evaluating qualitative research. Included articles were considered to have high quality with respect to their goals, designs, analyses, and results, providing useful knowledge on the topic (Table 1). The quality assessment was carried out in team sessions by all the authors. 
Table 1. Quality assessment of included studies (Joanna Briggs Institute, 2017)

\begin{tabular}{|c|c|c|c|c|c|c|c|c|c|c|}
\hline Article & \multicolumn{10}{|c|}{ Questions } \\
\hline Consonni and Petean (2013) & - & $\checkmark$ & $\checkmark$ & $\checkmark$ & $\checkmark$ & - & - & $\checkmark$ & $\checkmark$ & $\checkmark$ \\
\hline Golan and Leichtentritt (2016) & $\checkmark$ & $\sqrt{ }$ & $\checkmark$ & $\checkmark$ & $\checkmark$ & - & - & $\checkmark$ & $\sqrt{ }$ & $\sqrt{ }$ \\
\hline Lafarge et al. (2013) & - & $\checkmark$ & $\checkmark$ & $\checkmark$ & $\checkmark$ & - & $\checkmark$ & $\checkmark$ & $\checkmark$ & $\checkmark$ \\
\hline Leichtentritt and Mahat-Shamir (2017) & $\checkmark$ & $\checkmark$ & $\checkmark$ & $\checkmark$ & $\checkmark$ & $\checkmark$ & $\checkmark$ & $\checkmark$ & $\checkmark$ & $\checkmark$ \\
\hline Leichtentritt and Weinberg-Kurnik (2016) & $\checkmark$ & $\checkmark$ & $\checkmark$ & $\checkmark$ & $\checkmark$ & $\checkmark$ & - & $\checkmark$ & $\sqrt{ }$ & $\checkmark$ \\
\hline Maguire et al. (2015) & - & $\checkmark$ & $\checkmark$ & $\checkmark$ & $\checkmark$ & - & - & $\checkmark$ & $\checkmark$ & $\checkmark$ \\
\hline McGuinness (2015) & $\checkmark$ & $\checkmark$ & $\checkmark$ & $\checkmark$ & - & - & - & $\checkmark$ & $\checkmark$ & $\checkmark$ \\
\hline Abdel-Razeq and Al-Gamal (2018) & $\checkmark$ & $\checkmark$ & $\checkmark$ & $\checkmark$ & $\checkmark$ & $\checkmark$ & - & $\checkmark$ & $\checkmark$ & $\checkmark$ \\
\hline
\end{tabular}

Abbreviations: $\checkmark$ Yes - Unclear $\boldsymbol{X}$ No; Critical appraisal questions: (1) Is there congruity between the stated philosophical perspective and the research methodology? (2) Is there congruity between the research methodology and the research question or objectives? (3) Is there congruity between the research methodology and the methods used to collect data? (4) Is there congruity between the research methodology and the representation and analysis of data? (5) Is there congruity between the research methodology and the interpretation of results? (6) Is there a statement locating the researcher culturally or theoretically? (7) Is the influence of the researcher on the research, and vice-versa, addressed? (8) Are participants, and their voices, adequately represented? (9) Is the research ethical according to current criteria or, for recent studies, and is there evidence of Research Ethics Committee approval by an appropriate body? (10) Do the conclusions drawn in the research report flow from the analysis, or interpretation, of the data?

\subsection{Data abstraction and synthesis}

The interpretive meta-ethnographic method of Noblit and Hare (1988) was followed, which consists of seven steps: (1) getting started; (2) deciding what is relevant to the initial interest; (3) reading the studies; (4) determining how the studies are related; (5) translating the studies into one another; (6) synthesizing translations; and (7) expressing the synthesis. The studies were read independently by each author until all the authors were familiar with their contents (step 3). The primary articles were read and translated in alphabetical order by the surname of the principal author of the studies, ranking the first article as the richest in terms of data.

The main first order (participants' quotations) and second order (authors' interpretations) (Schütz, 1962) concepts were extracted across the full primary study by SFB and MJMF and recorded in a Microsoft Word table.

Using the constant comparison method (Strauss \& Corbin, 1990) (step 4), different concepts were compared by SFB and MJMF in search of similarities and contrasts, which led to the formation of new concepts and the adoption of existing concepts. This was done by systematically and sequentially comparing concepts using the registered study characteristics (year, location, methodology, aim, size and type of sample, type of loss, data collection methods, and key findings) as context for the comparisons.

In step 5, SFB and MJMF organized the concepts in conceptual piles and then discussed and reorganized these piles. The juxtaposition of the first- and second-order constructions through reciprocal and refutational translations led to the development of third-order constructions (Schütz, 1962) by the authors (SFB and MJMF), which included a new understanding of the phenomenon. CC, independently audited the analytical coherence of the findings.

Finally, in step 6, all the authors independently developed a storyline of the phenomenon (Noblit, 2016). These overarching explanations were then merged, discussed, and used to generate hypotheses to produce the line of argument synthesis (Atkins et al., 2008; France et al., 2019). 
The Confidence in the Evidence from Reviews of Qualitative research (CERQual) approach was used to show the degree of confidence in the review findings (Lewin et al., 2015). CERQual involves an assessment of the review findings in terms of four components: methodological limitations, coherence, relevance, and adequacy of data (File S2).

\section{RESULTS}

An overview of the 14 included studies is given in Table 2. The sample sizes of the studies ranged from 8-59 participants. Research was primarily conducted in Israel, Ireland, the United States of America, India, Jordan, Brazil, the United Kingdom, Denmark, and Australia. Ten articles featured women; one article had men as participants and three studies used couples as participants. The most common type of loss in the studies was TFA, followed by stillbirth, neonatal death and miscarriage. Interpretive research designs were more common than descriptive designs. Interviews, both semi-structured and in-depth, were used to collect the data.

The analysis revealed the line of argument Staying afloat in the storm. This metaphor represents the coping experience of parents following perinatal loss. Once the loss occurs, an emotional storm is triggered that parents must weather. What they use to stay afloat symbolizes the coping strategies. These strategies may vary throughout their grieving journey. The five themes that emerged were searching for the meaning of the loss, connecting with the baby, talking about the experience, looking to the future, and avoidance (Table 3). The CERQual assessment showed low confidence in talking about the experience and looking to the future, since these strategies were present in few studies. Searching for the meaning of the loss, avoidance and connecting with the baby showed moderate confidence, meaning it is likely that they reasonably represent parents' coping experiences following perinatal loss (File S2). Below, the themes are presented accompanied by quotations extracted from the articles, indicating if the quotation is from a mother or father. 
Table 2. Paper characteristics

\begin{tabular}{|c|c|c|c|c|c|c|}
\hline $\begin{array}{l}\text { Authors (year) } \\
\text { location }\end{array}$ & Methodology & Aim & Sample & Type of loss & $\begin{array}{l}\text { Data collection } \\
\text { methods }\end{array}$ & Key findings \\
\hline $\begin{array}{l}\text { Carolan and } \\
\text { Wright (2017), } \\
\text { USA }\end{array}$ & Phenomenology & $\begin{array}{l}\text { To perceive and describe the } \\
\text { experience of miscarriage of women } \\
\text { of advanced maternal age }\end{array}$ & $\begin{array}{l}10 \\
\text { women }\end{array}$ & Miscarriage & $\begin{array}{l}\text { Interview + } \\
\text { Ecomap }\end{array}$ & $\begin{array}{l}\text { Women experience miscarriage from a physical, emotional, temporal, and } \\
\text { social context that includes intense loss and grief, having a sense of otherness, a } \\
\text { continuous search for meaning, and feelings of regret and self-blame. }\end{array}$ \\
\hline $\begin{array}{l}\text { Consonni and } \\
\text { Petean (2013), } \\
\text { Brazil }\end{array}$ & $\begin{array}{l}\text { Qualitative } \\
\text { descriptive } \\
\text { exploratory study }\end{array}$ & $\begin{array}{l}\text { To investigate the grieving } \\
\text { experiences of women who } \\
\text { underwent TFA }\end{array}$ & $\begin{array}{l}10 \\
\text { women }\end{array}$ & TFA & $\begin{array}{l}\text { Semi-structure } \\
\text { interview }\end{array}$ & $\begin{array}{l}\text { Mothers sought explanations and meanings for the loss, with religious } \\
\text { responses and self-blame being very frequent. The mothers were and continued } \\
\text { to be linked to their children; the TFA, although being a choice to minimize the } \\
\text { pain of an inevitable loss, did not spare the women from experiences of great } \\
\text { suffering. }\end{array}$ \\
\hline $\begin{array}{l}\text { Golan and } \\
\text { Leichtentritt } \\
\text { (2016), Israel }\end{array}$ & Phenomenology & $\begin{array}{l}\text { To examine the meaning that women } \\
\text { who experience SB ascribe to their } \\
\text { loss in general and to the lost figure } \\
\text { in particular. }\end{array}$ & $\begin{array}{l}10 \\
\text { women }\end{array}$ & SB & $\begin{array}{l}\text { In-depth } \\
\text { interviews }\end{array}$ & $\begin{array}{l}\text { For women, the lost figure and the loss in general engender ambiguity both } \\
\text { internally and externally, in the women's social environment. }\end{array}$ \\
\hline $\begin{array}{l}\text { Gopichandran et } \\
\text { al. (2018), India }\end{array}$ & $\begin{array}{l}\text { Qualitative } \\
\text { research methods }\end{array}$ & $\begin{array}{l}\text { To explore the social, emotional, and } \\
\text { psychological impact of SB on } \\
\text { women and their families in the } \\
\text { Indian context. }\end{array}$ & $\begin{array}{l}8 \\
\text { women }\end{array}$ & SB & $\begin{array}{l}\text { In-depth } \\
\text { interviews }\end{array}$ & $\begin{array}{l}\text { Women who experienced SB were frustrated when they could not find the cause } \\
\text { and blamed various people in their lives. Women and their families perceived } \\
\text { poor quality of services provided in the health system and reported that the } \\
\text { HCPs were inconsiderate and insensitive. Coping mechanisms include: } \\
\text { isolation, immersion in work, placing maternal love on other children, the } \\
\text { anticipation of next pregnancy, and religiosity. }\end{array}$ \\
\hline $\begin{array}{l}\text { Kofod and } \\
\text { Brinkmann } \\
\text { (2017), Denmark }\end{array}$ & Qualitative study & $\begin{array}{l}\text { To analyse how grieving the loss of } \\
\text { an infant in contemporary Danish } \\
\text { culture is experienced, interpreted, } \\
\text { and enacted }\end{array}$ & $\begin{array}{l}13 \\
\text { couples }\end{array}$ & $\begin{array}{l}\text { SB and } \\
\text { neonatal death }\end{array}$ & $\begin{array}{l}\text { In-depth semi- } \\
\text { structured } \\
\text { interviews }\end{array}$ & $\begin{array}{l}\text { A normative ambivalence regarding the status of loss and the expression of } \\
\text { mourning, built on the basis of cultural standards, is suggested. Grieving the } \\
\text { loss of an infant requires a constant balancing in this ambivalent normative } \\
\text { landscape. }\end{array}$ \\
\hline $\begin{array}{l}\text { Lafarge et al. } \\
\text { (2013), UK }\end{array}$ & IPA & $\begin{array}{l}\text { To examine the coping strategies } \\
\text { women use both during and after a } \\
\text { TFA procedure. }\end{array}$ & $\begin{array}{l}27 \\
\text { women }\end{array}$ & TFA & $\begin{array}{l}\text { Qualitative } \\
\text { interview }\end{array}$ & $\begin{array}{l}\text { The coping strategies of women after TFA are: Remembering the baby, } \\
\text { receiving and providing emotional support, avoidance behaviors and looking to } \\
\text { the future. Women mostly used adaptive coping strategies but reported } \\
\text { inadequacies in aftercare, which challenged their resources. }\end{array}$ \\
\hline $\begin{array}{l}\text { Leichtentritt and } \\
\text { Mahat-Shamir } \\
\text { (2017), Israel }\end{array}$ & $\begin{array}{l}\text { Qualitative } \\
\text { hermeneutic } \\
\text { methodology }\end{array}$ & $\begin{array}{l}\text { To reach an interpretive } \\
\text { understanding of the continuing bond } \\
\text { experience among mothers who } \\
\text { underwent TFA. }\end{array}$ & $\begin{array}{l}28 \\
\text { women }\end{array}$ & TFA & $\begin{array}{l}\text { In-depth } \\
\text { interviews }\end{array}$ & $\begin{array}{l}\text { The results highlight two themes: (a) strategies for relinquishing connection } \\
\text { with the baby and (b) strategies for maintaining a postdeath relationship. }\end{array}$ \\
\hline $\begin{array}{l}\text { Leichtentritt and } \\
\text { Weinberg-Kurnik } \\
\text { (2016), Israel }\end{array}$ & Phenomenology & $\begin{array}{l}\text { To examine the experience of Israeli } \\
\text { fathers after TFA }\end{array}$ & 17 Men & TFA & $\begin{array}{l}\text { In-depth semi- } \\
\text { structured } \\
\text { interviews }\end{array}$ & $\begin{array}{l}\text { The results indicate that men's experiences in this arena are socially constructed } \\
\text { and limited by gender roles and expectations. The revealed themes address: (a) } \\
\text { the lack of a socially constructed terminology; (b) the unclear definition of the } \\
\text { feticide experience; (c) men's sense of obligation to protect themselves and } \\
\text { others from the procedure and its ramifications, and (d) the policies and } \\
\text { regulations used to exclude men from the feticide experience, and the strategies } \\
\text { they use to exclude themselves. }\end{array}$ \\
\hline
\end{tabular}


Maguire et al.

(2015), USA

Grounded theory

$\begin{array}{ll}\text { McGuinness } & \text { Focused- } \\ \text { (2015), Ireland } & \text { ethnography }\end{array}$

Meaney et al.

(2017), Ireland

Nuzum et al.

(2018), Ireland

IPA

Pitt et al. (2016),

Australia

Thematic analysis

Abdel-Razeq and

Al-Gamal (2018)

Phenomenology

Jordan

o provide an in-depth account of omen's embodied experiences of

prenatal diagnosis and TFA

To provide an in-depth and rich

description of the living experience

of the bereaved mothers after losing

newborns and analyse how bereaved

losing a newborn this grief changes over time.

This article discusses the findings carried out with mothers following late miscarriage, stillbirth, or

To gain detailed insight into their expectations of pregnancy and their experience of miscarriage diagnosis

To explore the lived experiences an personal impact of stillbirth on bereaved parents wom wome

Late

miscarriage,

$\mathrm{SB}$, and

neonatal death

10

women

+6 men

12

women

+5 men

59

women

12 women

$\mathrm{SB}$
Three around the termination decision, social isolation related to discomfort with 3 weeks, months, and 1

Face-to-face

interviews

abortion, and grief triggered by reminders of pregnancy.

The findings describe that the immediate postnatal period for bereaved mothers holds memories that will last forever and may influence the grieving process. highlights the importance of pregnancy to the majority of mothers and reaffirms the important role of a mother spending time with her baby involving husbands and partners and looking after other children. Normal grief stages were evident in the narratives of the bereaved mothers. It is important that mothering is acknowledged, supported, and validated following the loss of baby

Semi-structured There are six superordinate themes in relation to the participant's experience of miscarriage: acknowledgement of miscarriage as a valid loss, misperceptions of miscarriage, the hospital environment, management of miscarriage, support and coping, reproductive history and implications for future pregnancies

Semi-structured Stillbirth had a profound and enduring impact on bereaved parents. Four

$\begin{array}{ll}\text { Semi-structured } & \text { Stillirth had a profound and enduring impact on bereaved parents. Four } \\ \text { in-depth } & \text { superordinate themes relating to the human impact of stillbirth emerged from }\end{array}$ interviews superordinate themes relating to the human impact of stillbirth emerged
the data: maintaining hope, importance of the personhood of the baby, the data: maintaining hope, importance of the personhood of the baby,
protective care, and relationships (personal and professional). Bereaved parents protective care, and relationships (personal and professional). Bereaved parents
recalled in vivid detail their experiences of care following diagnosis of stillbirth and their subsequent care. The time between diagnosis of a life-limiting anomaly or stillbirth and delivery is highlighted as important for parents as they find meaning in their loss.

TFA In-depth Two key themes are presented below: Transitioning embodiment, and

interviews

vulnerable bodies in comfortable spaces.

Neonatal death Semi-structure interviews

Three main themes emerged from the analysis: longing and grieving, as natura emotional responses to the loss; adaptive work of coping, as the mothers internalized meanings to cope with their loss; and moving forward but with scar, as the mothers moved on with their lives while they carried the unforgettable memories of the newborns" death experience. 
Table 3. Metaphor, emerged themes and main stratified results

\begin{tabular}{|c|c|c|c|c|c|}
\hline & \multicolumn{5}{|l|}{ "Staying afloat in the storm" } \\
\hline & $\begin{array}{l}\text { Searching for the meaning of the } \\
\text { loss }\end{array}$ & $\begin{array}{l}\text { Talking about the } \\
\text { experience }\end{array}$ & $\begin{array}{l}\text { Looking to the } \\
\text { future }\end{array}$ & Avoidance & Connecting with the baby \\
\hline $\begin{array}{l}\text { Parents } \\
\text { gender }\end{array}$ & q & q & q & $\sigma$ & $\sigma$ \\
\hline $\begin{array}{l}\text { Type of } \\
\text { loss }\end{array}$ & MS, TFA, SB, ND & MS, TFA, SB & TFA & MS, TFA, SB, ND & MS, TFA, SB, ND \\
\hline $\begin{array}{l}\text { Cultural } \\
\text { context }\end{array}$ & USA, Brazil, India, Jordan & USA and India & UK & USA, Brazil, Israel, India, UK, Ireland, Jordan & Denmark, UK, Israel, Ireland, Australia \\
\hline $\begin{array}{l}\text { Key } \\
\text { aspects }\end{array}$ & $\begin{array}{l}\text { Sources: HCPs, religion, } \\
\text { superstitions, blame } \\
\text { (husband/family, HCPs and } \\
\text { themselves) and medical reasons. }\end{array}$ & $\begin{array}{l}\text { Talking with other causes: } \\
\text { Know other cases of loss, } \\
\text { establish social } \\
\text { connections, reduce social } \\
\text { isolation. } \\
\text { Talking to their social } \\
\text { circle is comforting and } \\
\text { allows reciprocal support. } \\
\text { Participating in support } \\
\text { groups produces } \\
\text { ambivalent feelings. }\end{array}$ & $\begin{array}{l}\text { To allow to close } \\
\text { stages of the } \\
\text { grieving process; to } \\
\text { search for positive } \\
\text { aspects of the loss }\end{array}$ & $\begin{array}{l}\text { How: Avoid contact with others and be distracted (with the } \\
\text { company of their social circle, performing routine } \\
\text { activities, returning to work, playing the role of mother } \\
\text { with other children, taking care of others, changing their } \\
\text { routine, and disconnecting from the baby). } \\
\text { Why: To protect themselves, not to worry about their } \\
\text { social environment and to avoid the reaction of others. } \\
\text { Consequences of avoidance: Storing of emotions, tension } \\
\text { in the couple, ignorance of the process and social isolation. }\end{array}$ & $\begin{array}{l}\text { They use tokens and symbolic acts to establish a } \\
\text { bond with the baby and to legitimize the loss. } \\
\text { Tokens: a pregnancy diary, memory box, } \\
\text { photographs. } \\
\text { Symbolic acts: lighting a candle, writing a post, } \\
\text { getting a tattoo, planting a tree, using the name } \\
\text { of their baby with the next child, spending time } \\
\text { with the baby, talking about the baby, visiting } \\
\text { places of remembrance, and attending acts of } \\
\text { remembrance. }\end{array}$ \\
\hline Articles & $\begin{array}{l}\text { Carolan and Wright (2017); } \\
\text { Consonni and Petean (2013); } \\
\text { Gopichandran et al. (2018); } \\
\text { Maguire et al. (2015); Abdel-Razeq } \\
\text { and Al-Gamal (2018) }\end{array}$ & $\begin{array}{l}\text { Carolan and Wright } \\
\text { (2017); Gopichandran et al. } \\
\text { (2018); Maguire et al. } \\
\text { (2015) }\end{array}$ & $\begin{array}{l}\text { Lafarge et al. } \\
(2013)\end{array}$ & $\begin{array}{l}\text { Carolan and Wright (2017); Consonni and Petean (2013); } \\
\text { Golan and Leichtentritt (2016); Gopichandran et al. (2018); } \\
\text { Lafarge et al. (2013); Leichtentritt and Mahat-Shamir } \\
\text { (2017); Leichtentritt and Weinberg-Kurnik (2016); } \\
\text { Maguire et al. (2015); Nuzum et al. (2018); Pitt et al. } \\
\text { (2016); Abdel-Razeq and Al-Gamal (2018) }\end{array}$ & $\begin{array}{l}\text { Kofod and Brinkmann (2017); Lafarge et al. } \\
\text { (2013); Leichtentritt and Mahat-Shamir (2017); } \\
\text { McGuinness (2015); Meaney et al. (2017); } \\
\text { Nuzum et al. (2018); Pitt et al. (2016) }\end{array}$ \\
\hline
\end{tabular}

Abbreviations: ( $($ )), women and men; $(\$)$, women; MS, miscarriage; ND, neonatal death; SB, stillbirth; TFA, pregnancy termination for fetal abnormality; UK, United Kingdom; USA, United States of America. 


\subsection{Searching for the meaning of the loss}

Mothers searched for the meaning of the loss to make sense of and gain control over the chaos that the loss generated rather than as a mechanism to satisfy or tolerate the pain (Carolan \& Wright, 2017). When mothers did not obtain an objective response from the HCPs about the cause of the loss (Gopichandran, Subramaniam, \& Kalsingh, 2018), some tried to make sense of their loss through religion (Consonni \& Petean, 2013). The causes they found in religion oscillated between a benevolent divine purpose or divine punishment (Abdel-Razeq \& Al-Gamal, 2018; Carolan \& Wright, 2017; Consonni \& Petean, 2013; Maguire et al., 2015). In Indian (Gopichandran et al., 2018) and Arabic (Abdel-Razeq \& Al-Gamal, 2018) cultures, some mothers took shelter in or renounced religion, depending on whether the answers provided by religion were comforting or not in their grieving process:

After the surgery they told me that the baby had passed away before the surgery. So, that kind of helped because I didn't feel like we did it or the doctor did it... I felt, like, God did it and that was what He wanted. Mother (Maguire et al., 2015).

Other resources used were superstition and blaming the husband and family, HCPs and themselves (Gopichandran et al., 2018; Maguire et al., 2015). Contrarily, mothers with a high educational level looked for meaning in medical causes (Gopichandran et al., 2018; Maguire et al., 2015):

We used to live in a haunted house previously. I got pregnant when I was living there. I think that is the reason for this baby's death. Mother (Gopichandran et al., 2018).

\subsection{Talking about the experience}

When mothers shared their loss with others, they discovered cases of loss that they did not know of beforehand. They realized that they were not the only ones that had experienced this situation. Indeed, they established a social connection and felt relieved of the burden of social isolation (Maguire et al., 2015):

\section{[...] [If you] start to tell people about what you experience [then] they would say, "Oh,} yeah. I know. We had one baby before and we lost [it too]. Mother (Maguire et al., 2015).

For mothers, talking with their close circle was comforting (Carolan \& Wright, 2017; Gopichandran et al., 2018). Specifically, the contact of mothers with others with similar experiences facilitated reciprocal support and reduced isolation (Lafarge, Mitchell, \& Fox, 2013; Maguire et al., 2015). As one mother said:

My mother-in-law was a huge influence. She really helped me because she experienced a miscarriage; she suffered a loss farther along than I was [...]. So, when it happened I was more comfortable talking to her. Mother (Carolan \& Wright, 2017).

Some mothers participated in online support groups, which caused ambivalent feelings based on their mood when reading the comments; some joined face-to-face support groups, which allowed them to situate themselves in their own healing process, although in the long run, it was not helpful to participate in support groups, which included people who had experienced a variety of losses (Lafarge et al., 2013).

Sometimes I found reading other people's accounts on the forum unhelpful as I felt guilty for not feeling as emotional or terrible as they did, but in time I was able to feel that this was positive, that I was coping and mentally strong. Mother (Lafarge et al., 2013). 


\subsection{Looking to the future}

In Lafarge et al. (2013), a tool that mothers used to cope with TFA was looking to the future. This strategy allowed mothers to achieve closure or move through the stages of the grieving process. For example, the funeral provided closure regarding the physical aspect of the loss. Looking to the future was also linked to searching for positive aspects in their experiences, such as by rationalizing, carrying out actions of good will and focusing on unresolved issues:

As closure was provided through the funeral, postmortem, due date passing, the first birthday, now it is time to move on with our lives. Mother (Lafarge et al., 2013).

\subsection{Avoidance}

In 11 papers, parents reported using avoidance strategies to deal with their loss and to protect themselves, since the pain of reliving the loss was avoided and blocked (Lafarge et al., 2013; Leichtentritt \& MahatShamir, 2017). Parents distracted their thoughts by mingling with their social circle, performing routine activities or changing their previous routine and returning to work (Abdel-Razeq \& Al-Gamal, 2018; Consonni \& Petean, 2013; Gopichandran et al., 2018; Lafarge et al., 2013). Specifically, mothers were distracted by playing the role of mother with other children (Gopichandran et al., 2018; Lafarge et al., 2013), whereas men took care of others (Leichtentritt \& Weinberg-Kurnik, 2016):

When you are busy caring for others... you also overlook yourself. Father (Leichtentritt \& Weinberg-Kurnik, 2016).

Some parents did not talk about the loss and did not relate to their social environment because they wanted to avoid the reactions of others and did not want to worry their social circle with manifestations of sadness (Consonni \& Petean, 2013; Gopichandran et al., 2018; Lafarge et al., 2013; Maguire et al., 2015; Pitt, McClaren, \& Hodgson, 2016). They also did not go to medical consultations (Pitt et al., 2016):

Women like me who have lost their babies are considered inauspicious. They (society) will talk badly if we even touch their normal babies. So, I do not go for any social functions. Mother (Gopichandran et al., 2018).

Culturally, some parents avoided expressing their grief due to the lack of social acceptance of these losses (Golan \& Leichtentritt, 2016; Leichtentritt \& Mahat-Shamir, 2017). In early losses, this avoidance was exacerbated, since expressions of mourning are prohibited in some social environments (Kofod \& Brinkmann, 2017):

People didn't want to hear... it's easier for everyone not knowing, not hearing... as if it just disappeared. Mother (Leichtentritt \& Mahat-Shamir, 2017).

Some parents also used strategies to disconnect from the baby, such as denying the existence of the child, not keeping memories and blocking thoughts and feelings about the baby (Carolan \& Wright, 2017; Lafarge et al., 2013; Leichtentritt \& Mahat-Shamir, 2017; Pitt et al., 2016). Some mothers even questioned the biological or genetic connection between them and the baby (Leichtentritt \& MahatShamir, 2017):

You convince yourself it is not really your genes... that genetics-wise you are okay. You make up stories which help you cope; you start believing them... that it's not yours. Mother (Leichtentritt \& Mahat-Shamir, 2017).

The use of avoidance strategies led to the suppression of emotions and the emergence of tensions in the couple due to differences in coping between the sexes (Gopichandran et al., 2018; Lafarge et al., 2013; Nuzum, Meaney, \& O'Donoghue, 2018). Attempts not to remember, see, talk, or experiment generated ignorance about certain aspects of the loss in parents. This meant that some of them later regretted not being present during the process (Leichtentritt \& Mahat-Shamir, 2017): 
I think [partner] had a lot closer connection to him than I had, because I suppose I see my time with him as, when he was born to when he was buried... I remember thinking he's my son but he's not (very upset). Father (Nuzum et al., 2018).

Additionally, parents experienced social isolation both because of the use of this strategy and because of the taboo that surrounds these losses (Carolan \& Wright, 2017; Lafarge et al., 2013; Meaney et al., 2017).

\title{
3.5 Connecting with the baby
}

Parents used resources to establish a bond with their child, which allowed them to maintain a connection with their child and legitimize their loss, even though it was painful. This was especially important in early losses, since these are ambiguous losses that are socially invisible, unknown, and not acknowledged (Leichtentritt \& Weinberg-Kurnik, 2016; Meaney et al., 2017):

\begin{abstract}
But the miscarriage itself, I'd say it was until then... and the whole discussion became a very public thing...it was only at that stage that I started to move on from it and that would have been five years, five years later and it was always something that would of upset me...it is hard to know what you are grieving for in a way because it is fleeting, you know the whole experience of being pregnant and then not being pregnant and thinking if I didn't remember this baby then who would. Father (Meaney et al., 2017).
\end{abstract}

Parents used tokens such as a pregnancy diary, especially in early losses where material memories were scarce, memory boxes and photographs (Kofod \& Brinkmann, 2017; Lafarge et al., 2013; Leichtentritt \& Mahat-Shamir, 2017; Pitt et al., 2016). Parents looked at these tokens privately, though in some cases, they shared them with their social environment so their baby would be socially acknowledged (Kofod \& Brinkmann, 2017; Pitt et al., 2016). For example, Lafarge et al.'s (2013) study, conducted in the UK, showed that even for men, the process of making a memory box was therapeutic because the time parents put into making the box was time taken to remember the baby:

My partner built a little box to put little mementos into. It took him many months to complete it as I think it was his time to think about the son he had lost. Mother (Lafarge et al., 2013).

Some parents performed rituals that connected them to the child. These symbolic acts involved lighting a candle, writing a post on a forum or doing something more permanent, like getting a tattoo or planting a tree (Lafarge et al., 2013; Leichtentritt \& Mahat-Shamir, 2017; Nuzum et al., 2018). The name of the child also connected it to them, as in some cases the parents were able to use it with the next child (Leichtentritt \& Mahat-Shamir, 2017; Nuzum et al., 2018). The performance of these rituals was culturally conditioned. In Jewish culture, parents could not enact public connection rituals, since mourning traditions are not accepted for early pregnancy losses (Leichtentritt \& Mahat-Shamir, 2017):

[I feel close to him in the graveyard] I just prefer it if there was no one else in the graveyard. I would definitely only feel it when I'm there on my own with him. Father (Nuzum et al., 2018).

Keeping the memory of the baby alive through talking about it in their social environment, visiting places of remembrance, and performing acts of remembrance provided mothers with closure and social acknowledgement of the baby (Lafarge et al., 2013; McGuinness, 2015). In advanced losses, spending time with the baby after birth favoured the existence and reinforcement of the bond (McGuinness, 2015; Nuzum et al., 2018):

I wanted to take him home. I wanted as much time with him as we could... suppose we knew we wouldn't have long with him before we buried him. Father (Nuzum et al., 2018). 


\section{DISCUSSION}

The synthesis of the qualitative evidence revealed in-depth how parents cope with perinatal loss. From the 14 included papers, we identified the overarching metaphor Staying afloat in the storm based on five themes that show the coping strategies used by parents after these losses. This metaphor symbolizes the emotional storm that these losses represent to parents and how they cope using different strategies to stay afloat.

For this discussion, the Multicultural Model of Coping after Pregnancy Loss (MMCPL) (Van, 2012) and the Motivational Theory of Coping (MTC) (Skinner, Edge, Altman, \& Sherwood, 2003) were found to be useful. We have merged these two theories with findings from different contexts and particularities. This has allowed us to present a deeper and more solid understanding of the coping experiences of parents following perinatal loss.

Van (2012) proposed the MMCPL, subsequently expanded (Fernández-Basanta, Van, Coronado, Torres, \& Movilla-Fernández, 2019), which establishes connectedness as a facilitator of coping, while disconnectedness is the central concept that inhibits coping. Applied to our results, connectedness could be associated with the connectivity with the baby, the search for the meaning of the loss and talking about the experience, whereas disconnectedness could be associated with avoidance.

Connectedness captures the conditions that facilitate or constrain coping with grief and related responses after pregnancy loss. According to the model, women who connect with their social environment tend to cope with their grief more effectively than women who do not. Connectedness exists between them and the people they know and have a personal connection with (Van, 2012).

Although the MMCPL was designed based on the coping experiences of women after a pregnancy loss, it fits with our aim. To fulfil this aim and to deepen and provide an improved theoretical framework, we use the MTC (Skinner et al., 2003). In this model, searching for the meaning of the loss, talking about the experience and connecting with the baby are considered adaptive coping strategies, while avoidance stands out as a maladaptive strategy. The experiences of connectedness/confrontation and disconnectedness/avoidance are a back-and-forth process and are not mutually exclusive.

Grief is a universal human reaction to the loss of a loved one, but social and cultural contexts influence the way grief is manifested and the coping strategies used (Brownlee \& Oikonen, 2004; Dallay, 2013; Fenstermacher \& Hupcey, 2013; Van \& Meleis, 2003). Perinatal losses are still considered taboo losses and are made invisible by social and health environments and some parents consequently perceive a lack of social and health support (France, Hunt, Ziebland, \& Wyke, 2013; Heazell, 2016). Furthermore, the literature supports the existence of a grief hierarchy (Kofod \& Brinkmann, 2017; Van \& Meleis, 2003), where grief expressions are accepted depending on the type of loss. For instance, in early losses, suffering is less socially accepted and parents may be forced to constantly negotiate the importance of the loss and to perform actions that legitimize the existence of their pregnancy/baby (Kofod \& Brinkmann, 2017; Leichtentritt \& Weinberg-Kurnik, 2016; Meaney et al., 2017; Sawicka, 2016). Logsdon and Davis (2003) affirm that for social support to be considered useful, it must fulfil the expectations of the one receiving the support and should come from a person of trust. When these conditions are not in place, the person may leave their needs unfulfilled instead of receiving support from another source.

In some cultures, social context and religion establish that femininity is synonymous with motherhood, which means that when childlessness occurs, a woman is deprived of her gender identity and some mothers may experience social isolation (Gerber-Epstein, Leichtentritt, \& Benyamini, 2009). However, religion can also have a protective effect for mothers, since it helps them make sense of the loss and cope with bereavement (Abdel-Razeq \& Al-Gamal, 2018; Roberts \& Lee, 2014). Our results show that when parents do not get answers that allow them to make sense of the loss, they may look to other resources, such as religion or superstition.

Looking to the future is a controversial strategy. In the MTC, it can be framed as an adaptive strategy, while in the MMCPL, it may belong to disconnectedness. Though this strategy represents a lowconfidence finding, the controversy regarding it can be explained by the stage in the grieving process and the type of loss. The advanced stages in the grieving process, where the pain intensity is lower, may favour the emergence of strategies such as rationalization or the search for positive aspects of the loss (Dávalos et al., 2008). However, in TFA, the loss is voluntary and involves decision-making. This 
decision-making may involve visualizing and rationalizing death as an escape from suffering (Boyraz, Horne, \& Waits, 2015).

The metaphor of Staying afloat in the storm symbolizes how parents cope with perinatal loss. Our findings showed that the five strategies are often conditioned by cultural, social, and individual factors, such as the taboo that surrounds these losses, the social expectations that condition grief expression, the lack of response from HCPs, the lack of social acknowledgment of the loss, the type of loss, and the stage in the grieving process. Giving emotional attention to these parents requires the provision of transcultural nursing care based on knowledge of the cultural context and background of the parents (Leininger, 1995). The provision of resources to prove the existence of the pregnancy/baby and of spaces where parents can express their grief is fundamental to legitimizing the loss (Martel \& Ives-Baine, 2018; O'Leary \& Warland, 2013). Therefore, care should contemplate an individual approach adapted to the needs of parents and not the creation of care protocols that generate barriers to the provision of comprehensive and individualized care. Nurses and midwives should lead out in the emotional care of parents experiencing perinatal loss by being the reference professional for parents (Capitulo, 2005), though the involvement of all HCPs is required. This study contributes to deepening the knowledge of the coping of parents following perinatal loss, which is important for developing nursing care in these situations. Furthermore, the MMCPL (Van, 2012) was confirmed and expanded, since our results develop in depth the factors that condition the use of coping strategies.

\subsection{Strengths and limitations}

This study's strengths lie in its comprehensive search strategy. This strategy ensured that the review is based on studies conducted in geographical contexts with unique and defining characteristics and on various types of losses, providing a more complete vision of the phenomenon. In addition, the studies were evaluated using the QARI criteria (Joanna Briggs Institute, 2017) and the review findings were assessed with CERQual (Lewin et al., 2015), confirming their transparency and reliability. This process improves the trustworthiness and applicability of the results in the clinical setting, decision-making and future research.

One of the weaknesses of this review is related to the composition of the samples. According to the literature (Cacciatore, Erlandsson, \& Rådestad, 2013) and the included studies, men are underrepresented. This makes it difficult to describe the male coping experience. Indeed, the profile of the informants in some of the studies was homogeneous, generating a limited view of the phenomenon. Another limitation refers to the generalization of the findings to countries outside western contexts. Taboos surrounding perinatal loss, social expectations regarding expressions of grief and the HCP-parent relationship can affect parents' coping experiences. In addition, meta-ethnography analysis can be challenging: even though the studies met the criteria to be included in this review, their objectives may not be in line with ours. Nevertheless, the meta-ethnography found both similarities and differences contributing to the refutational findings (i.e., religion).

The methodology used has been criticized for eliminating the original findings of the unique experience and extracting them from their context (Sandelowski, Barroso, \& Voils, 2007). Despite this limitation, the goal of meta-ethnography is not to summarize or aggregate information but to synthesize studies through an inductive and interpretive analysis, taking into account the context of the studies (Bondas \& Hall, 2007). The findings of this meta-ethnography are novel and offer a greater level of understanding of parents' coping experience following perinatal loss.

\section{CONCLUSION AND IMPLICATIONS}

The findings revealed five coping strategies used by parents following perinatal loss. The overarching metaphor symbolizes the emotional storm that the loss represents and the strategies that parents use to stay afloat during it, influenced by cultural, social, and individual factors. Understanding these coping experiences may improve the knowledge of HCPs in the provision of care to these parents. This metaethnography can inform nurse and midwife evidence-based practice by showing the importance of coping knowledge and care needs in the context of perinatal loss and by promoting the design and implementation of emotional care strategies. 
To expand knowledge of the experience of perinatal loss, in-depth research should approach samples that include men as participants. In addition, further research on informants with heterogeneous profiles will provide richer views of the phenomenon.

\section{ACKNOWLEDGEMENTS}

Not applicable.

\section{CONFLICT OF INTEREST}

The authors state that there is no conflict of interest.

\section{AUTHOR CONTRIBUTIONS}

S.F.-B., M.-J.M.-F.: Made substantial contributions to conception and design, or acquisition of data, or analysis and interpretation of data; S.F.-B., C.C., M.-J.M.-F.: Involved in drafting the manuscript or revising it critically for important intellectual content; S.F.-B., C.C., M.-J.M.-F.: Given final approval of the version to be published. Each author should have participated sufficiently in the work to take public responsibility for appropriate portions of the content; S.F.-B., C.C., M.-J.M.-F.: Agreed to be accountable for all aspects of the work in ensuring that questions related to the accuracy or integrity of any part of the work are appropriately investigated and resolved.

\section{REFERENCES}

Abdel-Razeq, N. M., \& Al-Gamal, E. (2018). Maternal bereavement: Mothers' lived experience of losing a newborn infant in Jordan. Journal of Hospice \& Palliative Nursing, 20(2), 137- 145. https://doi.org/10.1097/NJH.0000000000000417

Atkins, S., Lewin, S., Smith, H., Engel, M., Fretheim, A., \& Volmink, J. (2008). Conducting a metaethnography of qualitative literature: Lessons learnt. BMC Medical Research Methodology, 8(1), 21. https://doi.org/10.1186/1471-2288-8-21

Bondas, T., \& Hall, E. O. (2007). Challenges in approaching metasynthesis research. Qualitative Health Research, 17(1), 113-121. https://doi.org/10.1177/1049732306295879

Boyraz, G., Horne, S. G., \& Waits, J. B. (2015). Accepting death as part of life: Meaning in life as a means for dealing with loss among bereaved individuals. Death Studies, 39(1), $1-11$. https://doi.org/10.1080/07481187.2013.878767

Brownlee, K., \& Oikonen, J. (2004). Toward a theoretical framework for perinatal bereavement. British Journal of Social Work, 34(4), 517- 529. https://doi.org/10.1093/bjsw/bch063

Cacciatore, J. (2010). Stillbirth: Patient-centered psychosocial care. Clinical Obstetrics and Gynecology, 53(3), 691-699. https://doi.org/10.1097/GRF.0b013e3181eba1c6

Cacciatore, J., Erlandsson, K., \& Rådestad, I. (2013). Fatherhood and suffering: A qualitative exploration of Swedish men's experiences of care after the death of a baby. International Journal of Nursing Studies, 50(5), 664- 670. https://doi.org/10.1016/j.ijnurstu.2012.10.014

Capitulo, K. L. (2005). Evidence for healing interventions with perinatal bereavement. MCN, the American Journal of Maternal/Child Nursing, 30(6), 389- 396. https://doi.org/10.1097/00005721200511000-00007

Carolan, M., \& Wright, R. J. (2017). Miscarriage at advanced maternal age and the search for meaning. Death Studies, 41(3), 144- 153. https://doi.org/10.1080/07481187.2016.1233143

Consonni, E. B., \& Petean, E. B. (2013). Loss and grieving: The experiences of women who terminate a pregnancy due to lethal fetal malformations. Cien Saude Colet, 18(9), 2663-2670.

Cooke, A., Smith, D., \& Booth, A. (2012). Beyond PICO: The SPIDER tool for qualitative evidence synthesis. Qualitative Health Research, 22(10), 1435- 1443. https://doi.org/10.1177/1049732312452938

Côté-Arsenault, D., \& Marshall, R. (2000). One foot in-one foot out: Weathering the storm of pregnancy after perinatal loss. Research in Nursing \& Health, 23(6), 473- 485. https://doi.org/10.1002/1098-240X(200012)23:6<473:AID-NUR6>3.0.CO;2-I

Dallay, É. G. (2013). Le deuil périnatal de «l'enfant né sans vie». Annales Médico-psychologiques, Revue Psychiatrique, 171(3), 182- 188. 
Dávalos, E. G. M., García, S., Gómez, A. T., Castillo, L., Suárez, S. S., \& Silva, B. M. (2008). El proceso del duelo. Un mecanismo humano para el manejo de las pérdidas emocionales. Revista De Especialidades Médico-Quirúrgicas, 13(1), 28-31.

Ellis, A., Chebsey, C., Storey, C., Bradley, S., Jackson, S., Flenady, V., ... Siassakos, D. (2016). Systematic review to understand and improve care after stillbirth: A review of parents' and healthcare professionals' experiences. BMC Pregnancy Childbirth, 16, 16. https://doi.org/10.1186/s12884-016-0806-2

Fenstermacher, K., \& Hupcey, J. E. (2013). Perinatal bereavement: A principle-based concept analysis. Journal of Advanced Nursing, 69(11), 2389- 2400. https://doi.org/10.1111/jan.12119

Fernández-Basanta, S., Van, P., Coronado, C., Torres, M., \& Movilla-Fernández, M.-J. (2019). Coping after involuntary pregnancy loss: Perspectives of Spanish European women. OMEGAJournal of Death and Dying, 0030222819852849. https://doi.org/10.1177/0030222819852849

Flenady, V., Boyle, F., Koopmans, L., Wilson, T., Stones, W., \& Cacciatore, J. (2014). Meeting the needs of parents after a stillbirth or neonatal death. BJOG: An International Journal of Obstetrics \& Gynaecology, 121, 137- 140. https://doi.org/10.1111/1471-0528.13009

France, E. F., Cunningham, M., Ring, N., Uny, I., Duncan, E. A., Jepson, R. G., ... Booth, A. (2019). Improving reporting of meta-ethnography: The eMERGe reporting guidance. Journal of Advanced Nursing, 75, 1126-1139.

France, E. F., Hunt, K., Ziebland, S., \& Wyke, S. (2013). What parents say about disclosing the end of their pregnancy due to fetal abnormality. Midwifery, 29(1), 24-32. https://doi.org/10.1016/j.midw.2011.10.006

Frøen, J. F., Cacciatore, J., McClure, E. M., Kuti, O., Jokhio, A. H., Islam, M., \& Shiffman, J. (2011). Stillbirths: Why they matter. The Lancet, 377(9774), 1353- 1366.

Gerber-Epstein, P., Leichtentritt, R. D., \& Benyamini, Y. (2009). The experience of miscarriage in first pregnancy: The women's voices. Death Studies, 33(1), 1- 29. https://doi.org/10.1080/07481180802494032

Golan, A., \& Leichtentritt, R. D. (2016). Meaning reconstruction among women following stillbirth: A loss fraught with ambiguity and doubt. Health and Social Work, 41(3), 147- 154. https://doi.org/10.1093/hsw/hlw007

Gold, K. (2007). Navigating care after a baby dies: A systematic review of parent experiences with health providers. Journal of Perinatology, 27(4), 230- 237. https://doi.org/10.1038/sj.jp.7211676

Gopichandran, V., Subramaniam, S., \& Kalsingh, M. J. (2018). Psycho-social impact of stillbirths on women and their families in Tamil Nadu, India - a qualitative study. BMC Pregnancy Childbirth, 18(1), 109. https://doi.org/10.1186/s12884-018-1742-0

Heazell, A. E. (2016). Stillbirth-a challenge for the 21 st century. BMC Pregnancy and Childbirth, 16(1), 388. https://doi.org/10.1186/s12884-016-1181-8

Joanna Briggs Institute (2017). The Joanna Briggs Institute critical appraisal tools for use in JBI systematic reviews checklist for qualitative research. Retrieved from: http://joannabriggs.org/research/critical-appraisal-tools.html.

Kofod, E. H., \& Brinkmann, S. (2017). Grief as a normative phenomenon: The diffuse and ambivalent normativity of infant loss and parental grieving in contemporary Western culture. Culture \& Psychology, 23(4), 519- 533. https://doi.org/10.1177/1354067X17692294

Koopmans, L., Wilson, T., Cacciatore, J., \& Flenady, V. (2013). Support for mothers, fathers and families after perinatal death. Cochrane Database of Systematic Reviews, (6), CD000452. https://doi.org/10.1002/14651858.CD000452.pub3

Lafarge, C., Mitchell, K., \& Fox, P. (2013). Women's experiences of coping with pregnancy termination for fetal abnormality. Qualitative Health Research, 23(7), 924- 936. https://doi.org/10.1177/1049732313484198

Lawn, J. E., Blencowe, H., Waiswa, P., Amouzou, A., Mathers, C., Hogan, D., ... Draper, E. S. (2016). Stillbirths: Rates, risk factors andacceleration towards 2030. The Lancet, 387(10018), 587- 603. https://doi.org/10.1016/S0140-6736(15)00837-5

Lee, C. (2012). 'She was a person, she was here': The experience of late pregnancy loss in Australia. Journal of Reproductive and Infant Psychology, 30(1), 62- 76. https://doi.org/10.1080/02646838.2012.661849

Leichtentritt, R. D., \& Mahat-Shamir, M. (2017). Mothers' continuing bond with the baby: The case of feticide. Qualitative Health Research, 27(5), 665- 676. https://doi.org/10.1177/1049732315616626

Leichtentritt, R. D., \& Weinberg-Kurnik, G. (2016). No one sees the fathers: Israeli fathers' experience of feticide. Social Science and Medicine, 168, 159- 166. https://doi.org/10.1016/j.socscimed.2016.09.002

Leininger, M. M. (1995). Transcultural nursing: Concepts, theories, research \& practices. New York: McGraw-Hill, Inc.

Lewin, S., Glenton, C., Munthe-Kaas, H., Carlsen, B., Colvin, C. J., Gülmezoglu, M., ... Rashidian, A. (2015). Using qualitative evidence in decision making for health and social interventions: An approach to assess confidence in findings from qualitative evidence syntheses (GRADECERQual). PLoS Med, 12(10), e1001895. https://doi.org/10.1371/journal.pmed.1001895 
Logsdon, M. C., \& Davis, D. W. (2003). Social and professional support for pregnant and parenting women. MCN: the American Journal of Maternal/Child Nursing, 28(6), 371- 376. https://doi.org/10.1097/00005721-200311000-00008

López García de Madinabeitia, A. P. (2011). Duelo perinatal: Un secreto dentro de un misterio. Revista De La Asociación Española De Neuropsiquiatría, 31(1), 53- 70. https://doi.org/10.4321/S0211-57352011000100005

Maguire, M., Light, A., Kuppermann, M., Dalton, V. K., Steinauer, J. E., \& Kerns, J. L. (2015). Grief after second-trimester termination for fetal anomaly: A qualitative study. Contraception, 91(3), 234- 239. https://doi.org/10.1016/j.contraception.2014.11.015

Martel, S., \& Ives-Baine, L. (2018). Nurses' experiences of end-of-life photography in NICU bereavement support. Journal of Pediatric Nursing, 42, e38- e44. https://doi.org/10.1016/j.pedn.2018.05.011

Martinez-Serrano, P., Palmar-Santos, A. M., Solis-Munoz, M., Alvarez-Plaza, C., \& Pedraz-Marcos, A. (2018). Midwives' experience of delivery care in late foetal death: A qualitative study. Midwifery, 66, 127- 133. https://doi.org/10.1016/j.midw.2018.08.010

McGuinness, D. (2015). A shortened experience of motherhood...first of two parts. World of Irish Nursing \& Midwifery, 23(9), 63- 65.

Meaney, S., Corcoran, P., Spillane, N., \& O'Donoghue, K. (2017). Experience of miscarriage: An interpretative phenomenological analysis. British Medical Journal Open, 7(3), e011382. https://doi.org/10.1136/bmjopen-2016-011382

Noblit, G. (2016). How qualitative (or interpretive or critical) is qualitative synthesis and what we can do about this. A public lecture by Professor George W. Noblit, University of North Carolina at Chapel Hill, 2018.

Noblit, G. W., \& Hare, R. D. (1988). Meta-ethnography: Synthesizing qualitative studies, Vol. 11. Newbury Park, CA: Sage.

Nuzum, D., Meaney, S., \& O'Donoghue, K. (2014). The impact of stillbirth on consultant obstetrician gynaecologists: A qualitative study. BJOG: An International Journal of Obstetrics and Gynaecology, 121(8), 1020-1028.

Nuzum, D., Meaney, S., \& O'Donoghue, K. (2018). The impact of stillbirth on bereaved parents: A qualitative study. PLoS ONE, 13(1), e0191635. https://doi.org/10.1371/journal.pone.0191635

O'Leary, J., \& Warland, J. (2013). Untold stories of infant loss: The importance of contact with the baby for bereaved parents. Journal of Family Nursing, 19(3), 324- 347. https://doi.org/10.1177/1074840713495972

Pitt, P., McClaren, B. J., \& Hodgson, J. (2016). Embodied experiences of prenatal diagnosis of fetal abnormality and pregnancy termination. Reprod Health Matters, 24(47). https://doi.org/10.1016/j.rhm.2016.04.003

Puigarnau, A. P. (2008). Funciones psicológicas y tratamiento de las rumiaciones obsesivas en el duelo. Revista De La Asociación Española De Neuropsiquiatría, 28(102), 309- 323. https://doi.org/10.4321/S0211-57352008000200005

Roberts, L. R., \& Lee, J. W. (2014). Autonomy and social norms in a three factor grief model predicting perinatal grief in India. Health Care for Women International, 35(3), 285- 299. https://doi.org/10.1080/07399332.2013.801483

Sandelowski, M., Barroso, J., \& Voils, C. I. (2007). Using qualitative metasummary to synthesize qualitative and quantitative descriptive findings. Research in Nursing \& Health, 30(1), 99- 111. https://doi.org/10.1002/nur.20176

Sawicka, M. (2016). Searching for a narrative of loss: Interactional ordering of ambiguous grief. Symbolic Interaction, 40, 229- 246

Schütz, A. (1962). Collected papers, Vol. 1. The Hague, The Netherlands: Martinus Nijhoff.

Skinner, E. A., Edge, K., Altman, J., \& Sherwood, H. (2003). Searching for the structure of coping: A review and critique of category systems for classifying ways of coping. Psychological Bulletin, 129(2), 216. https://doi.org/10.1037/0033-2909.129.2.216

Strauss, A., \& Corbin, J. (1990). Basics of qualitative research. London: Sage publications.

Van, P. (2012). Conversations, coping, \& connectedness: A qualitative study of women who have experienced involuntary pregnancy loss. OMEGA-Journal of Death and Dying, 65(1), 71- 85.

Van, P., \& Meleis, A. I. (2003). Coping with grief after involuntary pregnancy loss: Perspectives of African American women. Journal of Obstetric, Gynecologic, \& Neonatal Nursing, 32(1), 28- 39. https://doi.org/10.1177/0884217502239798

World Health Organization (2006). Neonatal and perinatal mortality: Country, regional and global estimates. Retrieved from: http://www.who.int/iris/handle/10665/43444. 